\title{
Determination of Iron (II), Iron (III) and Total Iron in Some $\beta$-Thalassemia Patients using Different Analytical Techniques
}

\author{
N. A. Fakhre and D. K. Ali \\ Department of Chemistry, College of Education Scientific Departments, University of Salahalddin, Erbil, Iraq.
}

\begin{abstract}
There are many well-known analytical methods for determination of iron (II) and iron (III). A mong these methods: gravimetric, titrimetric, potentiometric, conductometric, batch and flow - injection spectrophotometric methods. In the present study, two batch spectrophotometric, atomic absorption spectrometric and biolabo kit methods have been used for determination of iron (II), iron (III) and total iron. The present methods have the advantages of high sensitivity, low cost reagent, low operation cost, simplicity, speed and their applications for determination of iron (II) and iron (III) in some serum samples of normal human and $\beta$-thallasemia patients in Erbil city. For the first time especially in Erbil city attempts were made to use zero, first and second derivative spectra to identify the serum samples of some $\beta$-thallasemia patients from the normal human serum samples due to the appearance and resolution of peaks in both cases.
\end{abstract}

Keywords: Determination, Iron, $\beta$-Thalassemia Patients, Different Analytical Techniques

\section{Introduction}

Iron as an essential element for living organisms, is oxygen transport and its role in oxidative-reductive reaction that utilize its alternative ferrous-ferric states(Sosa et al., 2008). The biological importance of iron is widely attributed to its chemical properties, there are two oxidative forms, ferrous $\left(\mathrm{Fe}^{2+}\right)$ and ferric $\left(\mathrm{Fe}^{3+}\right)$ iron, and iron is able to accept and donate electron. The living organisms should be able to control the internal amount of iron and to appropriately respond by changing its entry and storage processes. Failure in this control result in anemia or iron overload (Souza, 2005). Thalassemia is a pediatric inherited disease, it is a type of chronic, microcytic anemia (Sawh et al., 2003). It is gene-linked disease that can cause serious health problems because it can lead to the destruction of red blood cells (Vang et al., 2004). Classified in two major subtypes alpha and beta thalassemia which are results of mutation of the $\alpha$ - and $\beta$-globin genes respectively (5). $\alpha$ Thalassemia classified to four different forms, One gene deletion (silent carriers), Two - gene deletion ( $\alpha$ Thalassemia trait) Three - gene deletion $(\mathrm{HbH}$ disease and Four -gene deletion (hydrops fetalis). $\beta$-Thalassemia classified to three different forms $\beta$-Thalassemia minor (or heterozygous), $\beta$-Thalassemia intermedia (or $\beta+$ thalassemia) and $\beta$-Thalassemia major (or $\beta 0$ thalassemia). Many methods such as spectrophotometery, atomic absorption spectrometry, high performance liquid chromatography, polarography (34-36), ion selective electrode, high performance capillary electrophoresis have been proposed for determination of iron. This paper describes uv/visible spectrophotometric, atomic absorption spectrometric, derivative spectroscopy, biolabo kit methods and optimum conditions for the direct determination of iron (II) and iron (III) using 1,10phenanthroline and thiocyanate reagents. The aim of this study was to used some techniques (e.g uv/visible spectrophotometric methods, atomic absorption spectrometry, derivative spectroscopy and biolabo kit) for the determination of iron (II) and (III) ions and total iron in the blood serum samples of some of the $\beta$-thalassemia patients. Also, to distinguish between the samples of the normal humans and patients using zero and derivative spectroscopy.

\section{Materials and Methods}

Apparatus

Spectral measurements were carried out on a CECIL CE 3021UV/Visible digital spectrophotometer using 1-cm quartz cells A NV 203 spectrophotometer was used for all absorbance mesurments with a $1 \mathrm{~cm}$ glass cell. $\mathrm{pH}$ 


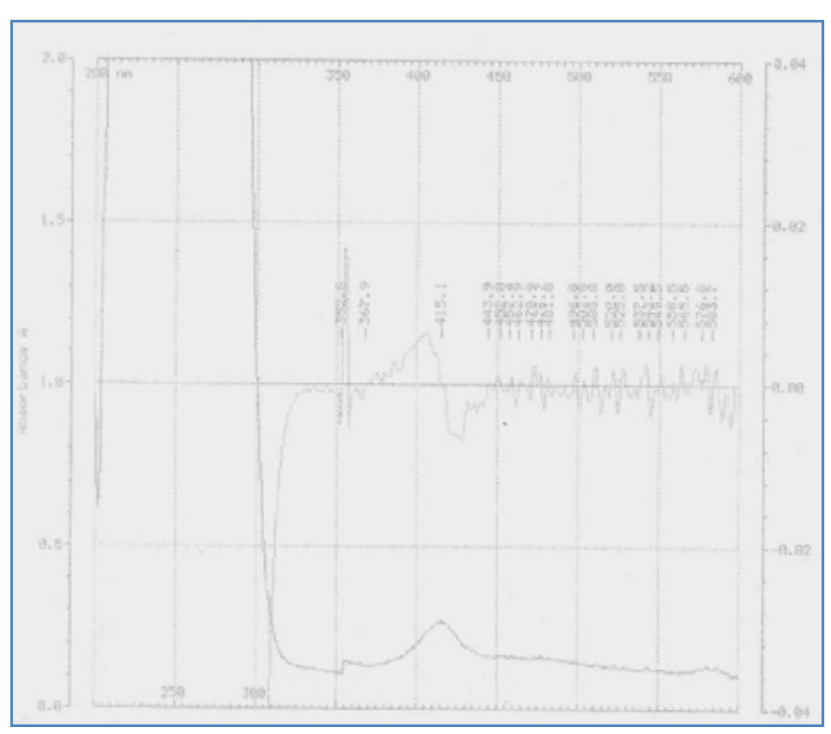

Fig. 1. First derivative spectrum of diluted 1:10 normal human serum.

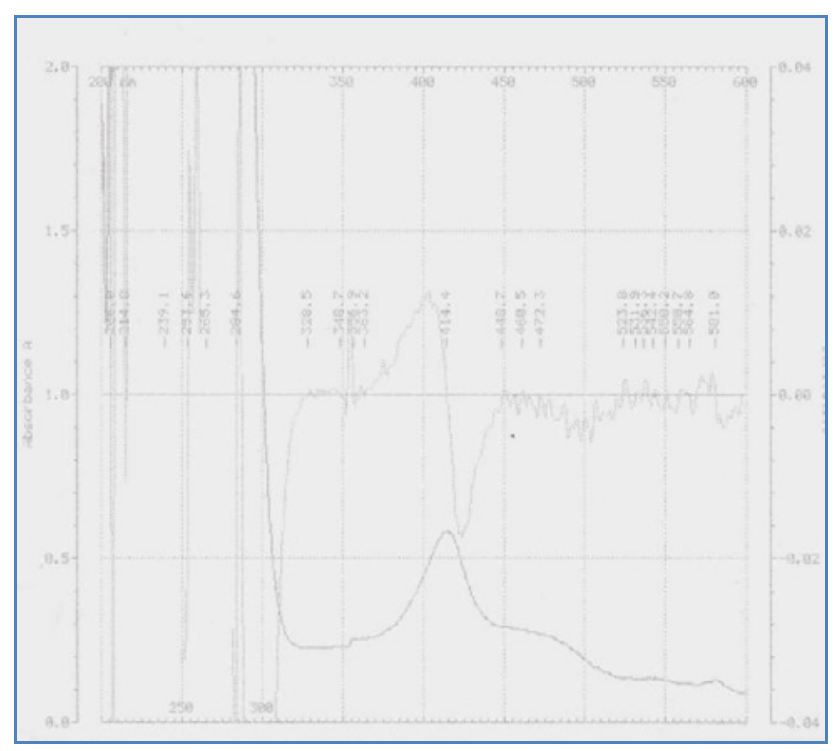

Fig. 2. First derivative spectrum of diluted 1:10 $\beta$ thalassemia human serum.

meter 7020 ( England ) was used to measure pH values. SP 9 Atomic absorption spectrophotometer Philips with iron hallow cathode lamp at wavelength $248.3 \mathrm{~nm}$ was used. Chemicals used are of the highest purity available.

\section{Results and Discussion}

\section{Simultaneous determination of iron (II) and iron (III)}

Synthetic solutions were prepared, containing $5.0 \mu \mathrm{g} / \mathrm{ml}$ of iron (II) and different amounts of iron (III). It was found that iron (III) can determined in the presence of $5.0 \mu \mathrm{g} / \mathrm{ml}$ of iron (II) within the concentration range $2.0-10.0 \mu \mathrm{g} / \mathrm{ml}$ iron (III).
Simultaneous determination of iron (II) and iron (III)

Synthetic solutions were prepared, containing $5.0 \mu \mathrm{g} / \mathrm{ml}$ of iron (II) and different amounts of iron (III). It was found that iron (III) can determined in the presence of $5.0 \mu \mathrm{g} / \mathrm{ml}$ of iron (II) within the concentration range $2.0-10.0 \mu \mathrm{g} / \mathrm{ml}$ iron (III).

\section{Simultaneous determination of iron (III) and iron (II)}

Synthetic solutions were prepared, containing $5.0 \mu \mathrm{g} / \mathrm{ml}$ of iron (III) and different amounts of iron (II). It was found that iron (II) can be determined in the concentration range of $3.0-5.5 \mu \mathrm{g} / \mathrm{ml}$ depending upon the decreasing of the absorbance of iron (III) thiocyanate complex.

\section{Simultaneous determination of iron (III) and iron (II)}

Synthetic solutions were prepared, containing $5.0 \mu \mathrm{g} / \mathrm{ml}$ of iron (III) and different amounts of iron (II). It was found that iron (II) can be determined in the concentration range of $3.0-5.5 \mu \mathrm{g} / \mathrm{ml}$ depending upon the decreasing of the absorbance of iron (III)-thiocyanate complex.

\section{Atomic absorption method}

The AAS method is characterized by excellent selectivity and good detection limit under optimum condition and relative freedom from interferences (42).

The calibration curves obtained showed good linearity over the range $1.0-5.0 \mu \mathrm{g} / \mathrm{ml}$ of iron. The molar absorptivity $0.11 \times 1041 \mathrm{~mol}^{-1} \mathrm{~cm}^{-1}$ and the detection limit is $0.90 \mu \mathrm{g} / \mathrm{ml}$.

\section{Zero and derivative spectroscopic studies}

The zero, first and second derivative spectra of some of the normal human and $\beta$-thalssemia patient serum samples were recorded. Figs. (1-4), are examples of the spectra of normal and patients serum samples, in which the normal human spectra show maximum absorptions at 417 and $280.5 \mathrm{~nm}$, while the spectra of patient serum samples show the same maximum absorption at $417 \mathrm{~nm}$ with a shoulder after $450 \mathrm{~nm}$. The sharp and smooth peak at $280.5 \mathrm{~nm}$ in the case of the spectra of normal human serum samples converted to multi peaks at the same region, in the case of $\beta$-thalssemia patients.

As expected there are resolution in the peaks and sharper peaks are obtained for the serum samples of $\beta$-thalssemia patients than the normal human. Therefore, either zero, first and second derivative spectra may be used for distinguish the serum samples of normal human and $\beta$-thalssemia patients. 


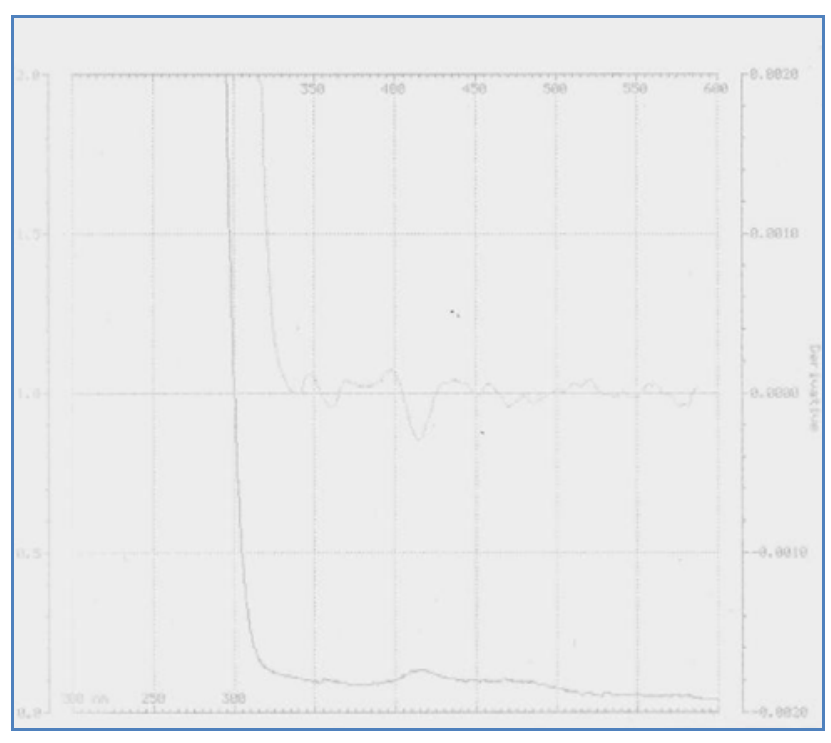

Fig. 3. Second derivative spectrum of diluted 1:10 $\beta$ thalassemia human serum.

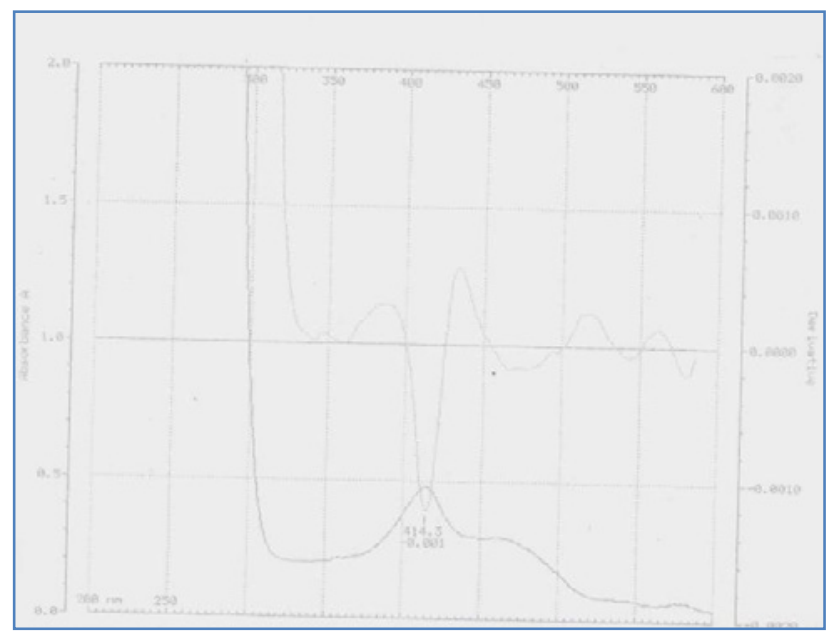

Fig. 4. Second derivative spectrum of diluted 1:10 $\beta$ thalassemia human serum.

\section{Conclusion}

In the present study, two batch spectrophotometric, atomic absorption spectrometric and biolabo kit methods have been used for determination of iron (II), iron (III) total iron. In addition zero, first and second derivative spectra were used to distinguish of the some serum samples of normal human and $\beta$-thallasemia patients. In the present investigation the total iron was determined in the mentioned serum samples using atomic absorption spectrometric method and biolabo kits. The results showed that atomic absorption spectrometry is more sensitive and accurate than the biolabo kits which are used in local laborites in Erbil city.

For the first time especially in Erbil city attempts were made to use zero, first and second spectra to identify the serum samples of some $\beta$-thallasemia patients from the normal human serum samples due to the appearance and resolution of peaks in both cases.

\section{References}

Sawh R. N., M. Martin and D. Baniewicz, Anita J. Catlin, (2003), 29(6), 447.

Sosa J. M., I. Samarzija. L. Honovic and B. Jurisic, Acta Pharm., (2008), 58, 231.

Souza A. M. D., Einstein, (2005), 3(2), 123.

Van P. g, O. Zongrum, R. Sindhuphak and N. Dusitsin, Hmong studies J., (2004), 8, 2-3. 